\title{
An assessment of the aversive nature of an animal management procedure (clipping) using behavioral and physiological measures
}

\author{
Kelly Yarnell ${ }^{\mathrm{a}}$, Carol Hall ${ }^{\mathrm{a}}$, Ellen Billett ${ }^{\mathrm{b}}$ \\ ${ }^{a}$ Nottingham Trent University, School of Animal, Rural and Environmental Sciences, \\ Brackenhurst Campus, Southwell, Nottinghamshire, NG25 0QF, UK \\ ${ }^{\mathrm{b}}$ Nottingham Trent University, School of Science and Technology, Clifton Campus, \\ Nottingham, Nottinghamshire, NG11 8NS, UK
}

*Corresponding author: carol.hall@ntu.ac.uk

Telephone: +44 (0) 1158485212

\begin{abstract}
Animal management often involves procedures that, while unlikely to cause physical pain, still cause aversive responses. The domestic horse (Equus caballus) regularly has excessive hair clipped off to facilitate its use as a riding / driving animal and this procedure causes adverse behavioral responses in some animals. The aim of this study was to compare behavioral and physiological measures to assess the aversive effect of this procedure. Ten horses were selected on the basis of being either compliant $(\mathrm{C}$ : $\mathrm{n}=5$ ) or non-compliant (NC: $\mathrm{n}=5$ ) during this procedure. The horses were subjected to a sham clipping procedure (SC: where the blades had been removed from the clippers) for a period of ten minutes. Measures were taken pre, during and post SC (-10 minutes to +30 minutes) and mean values calculated for ALL horses and for C and NC separately. Behavioral activity was scored (scale 1-5) by twenty students from video footage in (phase / group-blind scoring). Heart rate (HR), salivary cortisol and eye temperature were monitored throughout the procedure. The NC horses were found to be significantly more behaviorally active / less relaxed throughout the trial than $\mathrm{C}$ horses $(\mathrm{p}<0.05)$ with the greatest difference occurring during the SC procedure $(\mathrm{p}<0.01)$. NC horses were more active / less relaxed during, compared with pre or post SC $(\mathrm{p}<0.05)$, but showed no behavioral difference pre and post SC. HR of the $\mathrm{NC}$ horses was higher than that of the $\mathrm{C}$ horses throughout the trial but only significantly so after ten minutes of SC $(\mathrm{p}<0.01)$. ALL horses showed a significant increase in HR between +5 and +10 minutes into the procedure $(\mathrm{p}<0.05)$. There was a significant increase in salivary cortisol concentration in ALL horses post procedure
\end{abstract}


$(\mathrm{p}<0.01)$ with levels peaking at 20 minutes post SC. No significant differences in salivary cortisol concentration between $\mathrm{C}$ and $\mathrm{NC}$ were found at any stage of the trial. Eye temperature increased significantly in ALL horses during SC, peaking at +10 minutes into the procedure $(\mathrm{p}<0.05)$ and then decreased substantially when SC had ceased $(\mathrm{p}<0.01)$. Although no significant differences were found between $\mathrm{C}$ and $\mathrm{NC}$ per se, there was a significant interaction between group and phase of trial $(\mathrm{p}<0.05)$ with the NC group showing a greater decrease in eye temperature post SC. There was a significant positive correlation between changes in salivary cortisol concentration and eye temperature $(\mathrm{p}<0.01)$ but no correlation between any of the other measures. Although the behavioral response of $\mathrm{C}$ and $\mathrm{NC}$ to this procedure was significantly different the physiological responses indicated that ALL horses found the procedure aversive. Eye temperature could be used as an objective and immediate measure of how an animal is responding to a specific situation in order to evaluate management procedures and adapt them where appropriate to reduce the negative impact on animal health and welfare.

Key words; thermography, eye temperature, cortisol, horse, welfare, clipping

\section{Introduction}

To assess the mental state and consequently the welfare of domestic and captive animals a number of different physiological and behavioral parameters are used. Although behavior potentially offers an immediate means of assessing the response of an animal to environmental features and/or procedures, the accurate interpretation of behavioral signs requires corroboration by means of physiological evidence. In prey species in particular (such as the horse), outward behavioral signs of fear or distress may be masked as a means of survival and therefore will not always provide clear evidence of underlying mental state [1,2]. In addition, some domestic animals, of which the horse is a prime example, will have undergone training to increase their acceptance of potentially aversive procedures and their subsequent lack of response may not reflect the animal's subjective experience [3]. The physiological assessment of negative experiences in animals has to date been based mainly on changes in hormone levels and heart rate, although such measures are not without limitation. 
Elevation of the stress hormone cortisol is a currently accepted indicator of stress and has been used to assess how animals respond to environmental conditions and procedures [4]. However, blood sampling for plasma cortisol analysis requires the animal to be restrained and may be perceived as stressful thus confounding results [4,5]. A less invasive means of obtaining cortisol is from saliva. Unlike the cortisol in plasma (a proportion of which is bound to proteins and is inactive / non-bio available and unable to exert a biological effect during hypothalamic-pituitary-adrenocortical response) only the unbound cortisol passes from the blood into the salivary glands and therefore, the cortisol measured in the saliva will reflect levels of unbound, biologically available plasma cortisol [6]. Hormones enter saliva by a variety of mechanisms but for unconjugated steroids, including cortisol the route is rapid diffusion through the cells of the salivary glands and as such their concentration is independent of the rate of saliva flow [7,8]. Studies report close correlations between free cortisol in plasma and salivary cortisol levels in species including the horse $[9,10]$ and research suggests the time taken for salivary cortisol levels to increase post stressor is similar to that in plasma [11]. In both cases the delay between stressor and hormone elevation means this measure cannot be used to assess the immediate response to a specific stimulus, only to the overall situation. Other factors such as time of day [12] and level of activity / exercise [13] have been shown to affect cortisol level. In addition, the assessment of cortisol levels require laboratory analysis which limits application both in terms of the time delay in accessing results and in the resources required.

Changes in skin temperature have been shown to be associated with both clinical and emotional responses in humans and other animal species. These surface temperature changes are the consequence of changes in peripheral blood flow as a result of vasoconstriction or dilation caused by activation of the sympathetic nervous system [14]. Rapid changes in blood flow due to sympathetic activation and stimulation of the hypothalamic-pituitary-adrenocortical (HPA) axis associated with the stress response will alter the amount of radiated heat and the associated changes in surface temperature can be measured non-invasively using infrared thermography (IRT) [15]. In humans the subjective experience of fear was found to be associated with peripheral vasoconstriction and a resultant significant decrease in finger temperature [16]. In rhesus monkeys (Macaca mulatta) a decrease in nasal skin temperature was found to occur following exposure to a potentially threatening stimulus (a person in a 
laboratory coat with a catching net) and was concluded to indicate a change from a neutral to a negative mental state [17].

Activation of the sympathetic nervous system and the resultant redistribution of blood in preparation for 'flight or fight' have also been shown to result in surface temperature changes in non-primate species. When sheep (Ovis aries) were exposed to a number of different stressors, including prolonged periods of exercise and isolation, decreases in ear-pinna temperature (resulting from diversion of blood from peripheral structures) were found to occur that correlated with other measures such as increased heart rate and salivary cortisol concentrations [18]. The use of IRT to monitor changes in surface temperature provides a means of assessing the mental state of animals that is both immediate and non-invasive. However, in species that have varied coat coloration and thickness, and whose coat may contain different levels of moisture, surface temperature will be affected and will not solely indicate underlying blood flow and metabolism [19]. Changes in temperature of the eye and surrounding area have been found to be associated with aversive procedures in some species and this area is less affected by coat variations so offers the best potential for accurate monitoring of emotional responses. In the study of rhesus monkeys (Macaca mulatta) by Nakayama et al. [17] the decrease in nasal temperature was associated with an increase in temperature on the eyelids and adjacent area. Significant changes in eye temperature in response to stressful procedures have been found in other species, possibly as a result of increased dilation of ocular blood vessels and increased visual attention / orientation. Acute stress has been assessed using IRT in elk during velvet antler removal [20] and cows during disbudding [15]. Both studies report significant changes in eye temperature in response to the treatments as well as increases in plasma and salivary cortisol. A positive correlation between maximum percentage increase in plasma and salivary cortisol levels and maximum eye temperature was observed in an ACTH challenge in horses with the association between salivary cortisol and eye temperature being the strongest [21].

Procedures deemed necessary as part of the management of domestic (and other) species, while not inherently painful, may cause the animal distress. Behavioral responses do not always reflect the level of distress and this is further confounded in animals that have been trained to accept such procedures. By devising a means of evaluating the impact of management practices and procedures on an animal, 
adaptations that improve the subjective experience and consequent well-being of the animal can be made. As a result the occurrence of stress-related health problems [22] and the development of abnormal behavior patterns [23,24] may be reduced. Behavior expressed by a distressed animal also increases the risk of injury to handlers [25] so this evaluation also has the potential to improve human safety. Activity levels in fearful, restrained animals often increase and may become erratic as the animal tries to escape. Physiological responses to fear-eliciting stimuli, in particular increased heart rate, have been used to support the interpretation of such behavior [26]. However, such increases relate to activity level per se, so the results of such measures should be interpreted with care.

The practice of clipping excessive hair from horses in preparation for ridden work is a commonly adopted procedure that, while unlikely to be causing the animal pain, often causes signs of increased activity and distress [27,28,29]. The aim of this study was to evaluate the use of monitoring changes in eye temperature in horses using IRT while undergoing a 'sham' clipping procedure as a means evaluating their response.

Heart rate, salivary cortisol and behavioral responses were also recorded. Salivary cortisol has been found to reflect plasma cortisol levels in the horse [30,31] and one of the main advantages of measuring cortisol in saliva is that it is non invasive and unlikely to cause stress, particularly in domestic horses that are habituated to having their mouth handled on a daily basis for fitting of riding and training equipment, grooming and dental treatment. If eye temperature changes are found to correlate with the salivary cortisol response then IRT could be used to provide an immediate and non-invasive physiological measure to allow a more accurate interpretation of the behavioral response to a range of procedures in the horse and other species. Increases in heart rate have been associated with responses to aversive conditions in a range of species including the horse [26], but the effect of movement on this measure can limit its use. Again, IRT may offer a valuable alternative means of gathering such evidence.

\section{Materials and methods}

\subsection{Subjects}

The subjects were ten riding horses of mixed breed (Equus caballus, 7-11 years old, 4 mares and 6 geldings) from the Brackenhurst Equestrian Centre, Nottingham Trent 
University. All of these horses were clipped on a regular basis and were selected by the yard manager on the basis of either being behaviorally compliant during clipping (C: $\mathrm{n}=5 ; 2$ mares, 3 geldings) or having regularly shown behavioral signs of distress during clipping and being non-compliant (NC: $n=5 ; 2$ mares, 3 geldings). The study was carried out at the Brackenhurst Equestrian Centre, Nottingham Trent University and all horses involved in the study were ridden by students for up to two hours per day. However, on study days they were not ridden or used for practical lessons. Horses were housed in individual stables but could make auditory and visual contact with other horses stabled on the yard. The study was carried out in accordance with the ethical review policy of Nottingham Trent University.

\subsection{Design}

The response of the ten horses to a sham clipping procedure was assessed using behavioral and physiological measures (heart rate, salivary cortisol, eye temperature and core temperature). Sham clipping was carried out in an enclosed barn familiar to all of the horses but not generally used for the clipping procedure. The full clipping procedure would normally take in excess of 1 hour to carry out but this was deemed unnecessary for the current study which aimed at evaluating the potential for the use of IRT, rather than an in-depth study of the clipping process. Sham clipping was carried using guarded electric clippers (Lister, UK) with the blades removed. The horses were selected on the basis of their previous behavioral response to the clipping procedure to allow evaluation of this attribution of discomfort or not by means of the range of measures used. The results of each measure were compared for $\mathrm{C}$ and $\mathrm{NC}$ horses. All of the horses were trained to stand tied up using head collars and lead ropes for handling and management procedures. Prior to the sham clipping the horse was led to the test barn (by the same handler), tied up and allowed to acclimatize to this environment for ten minutes. Baseline recordings were then taken for each measure (behavior, salivary cortisol and eye temperature). The same measures were taken at each stage of the study: baseline, sham clipping, post sham clipping; at intervals appropriate for that measure (see section 2.4). Ambient temperature was monitored for the duration of the study (Lascar EL-USB-2) with the temperature logger set to record at five minute intervals, to correspond with IRT sampling to test for potential environmental effects on this measure. 


\subsection{Sham clipping procedure}

Sham clipping commenced 10 minutes after the baseline measures had been taken and continued for a period of 10 minutes. The operator of the clippers was experienced in the procedure, remained silent for the duration of the sham clipping and at no time verbally or physically comforted, coaxed or rewarded the horse. The clippers were placed on different areas of the body as follows (in the same order and duration for each horse): on the cranial crest of the neck (two minutes each side), flanks (two minutes each side) and each front leg (one minute per leg). Although no hair was removed the auditory and tactile sensation (vibration) of the clippers was apparent. It has been shown that aversive responses to clipping can be reduced by habituation to related auditory stimuli [29], so this sham clipping was deemed to be sufficient to elicit a behavioral / physiological response.

\subsection{Data acquisition and analysis}

\subsubsection{Behavioral assessment}

Behavior was recorded using a hand held video camera (Hitachi DVD/HD digital video camera) mounted on a tripod sited at a distance of approximately five meters from the horse. The camera was sited laterally to the horse and the distance allowed the whole body to remain in shot throughout the procedure. The camera was set up prior to the horse being taken to the test location in order for habituation to the equipment to occur prior to baseline behavioral scoring. Recording commenced immediately after the 10 minute acclimatization period and ceased 10 minutes after the sham clipping procedure had ended. The first five minutes of the footage from the different test phases were uploaded to a PC using an USB interface (baseline, sham clipping, post sham clipping) and saved for playback in Windows Media Player for Windows Xp for assessment. Clips of five minutes were selected to provide a standardized sample of behavior without the inclusion of physiological measures (e.g. saliva collection). These clips were numbered to allow for identification then replayed in a random order where observers were blind to the phase of the trial (baseline or post sham-clip) apart from the actual clipping phase.

Behavior was scored according to level of activity / relaxation and the scores and associated behaviors are shown in Table 1. The video clips were shown to twenty BSc Equine Science students in a blind random order of horse / phase of the trial and they 
assigned scores to each horse / phase combination. These scores were used to calculate mean activity scores for each horse at each phase of the trial.

Table 1: Behavioral scores and associated behavior ${ }^{\mathrm{a}}$

\begin{tabular}{cl}
\hline $\begin{array}{l}\text { Behavioral } \\
\text { score }\end{array}$ & Description of associated behavior \\
\hline $\mathbf{1}$ & $\begin{array}{l}\text { Very relaxed stance, lowered head, relaxed lower lip, eyes half } \\
\text { closed, ears turned to side. }\end{array}$ \\
$\mathbf{2}$ & $\begin{array}{l}\text { Relaxed stance, absence of restless behavior, very little movement. } \\
\mathbf{3}\end{array}$ \\
$\mathbf{4}$ & $\begin{array}{l}\text { Neutral stance, absence of whole body movement but vigilant head } \\
\text { and ears. } \\
\text { Active with some restless behavior, movement of head, neck and } \\
\text { ears including head raising and/or snorting. }\end{array}$ \\
$\mathbf{5}$ & $\begin{array}{l}\text { High degree of activity, very restless, raising of the head, whole } \\
\text { body movement including feet. }\end{array}$ \\
\hline
\end{tabular}

${ }^{a}$ The table lists descriptions of behavior that relate to increasing activity of the restrained horse, indicative of attempted avoidance / escape. The attributed scores range from 1 (low degree of activity / high degree of relaxation) to 5 (high degree of activity / avoidance attempts).

All statistical analyses conducted throughout this study were carried out using IBM SPSS Statistics 19. Two-tailed analyses were used in all calculations. Non-parametric analyses were used for the behavioral score data as one of the data sets varied significantly from the normal distribution (post sham clipping: Kolmogorov-Smirnov test $\mathrm{p}=0.043$ ). Behavior of $\mathrm{C}$ and $\mathrm{NC}$ horses was compared at each phase of the trial (baseline, sham clipping, post sham clipping) using Mann Whitney-U test with the approximate effect size being calculated for each $(\mathrm{r}=\mathrm{z} /$ square root of $\mathrm{N}$, where $\mathrm{N}=$ 10). Behavior at each of the phases of the trial was compared using the Friedman test, with comparisons between each phase (baseline-sham clipping; baseline-post sham clipping; sham clipping-post sham clipping) being made using the Wilcoxon test. Differences in behavior at each phase were investigated for the whole group and for $\mathrm{C}$ and NC separately. 


\subsubsection{Monitoring heart rate}

Heart rate was monitored using a Polar Equine RS800G3 heart rate monitor. This consists of a wireless textile transmitter in the form of an elasticized surcingle with two interwoven electrodes. The electrodes are made from conductive elastic fibers enabling them to adapt to the movement of the horse and ensure consistent contact with the skin. The surcingle was secured on the horse and the interwoven electrodes were positioned in the region of the upper left thorax and the ventral midline. Electrode gel was applied to the electrodes on the surcingle and their associated points on the horse to improve contact and enhance electrical conductivity. A detachable transmitter was clipped onto the surcingle. This communicates with the electrodes and transmits heart rate data to a receiver that has the capacity to store up to 90 hours of heart rate data. The receiver was also attached to the surcingle. Data stored in the receiver was later uploaded to PC based analytical software (Polar Pro-Trainer Equine Edition) using an infrared interface. Heart rate was logged every five minutes from five minutes pre onset of sham clipping until thirty minutes post onset of sham clipping.

Mean heart rate (HR) for each sampling point (C and NC groups) was calculated in Excel. Distribution of heart rate data varied significantly from the normal distribution (Kolmogorov-Smirnov test: $\mathrm{p}<0.05$ ) and non-parametric analyses were used. Differences in HR between groups (C and NC) were assessed for each time point (Mann Whitney-U test). The overall effect of time within the trial was assessed for each group of horses (C and NC) and overall (Friedman test) with specific differences between individual phases being further explored where appropriate (Wilcoxon test).

\subsubsection{Collection and analysis of salivary cortisol}

Saliva was collected using the commercially available salivette ${ }^{\circledR}$ (Sartedt, UK). These were designed for human use and were modified to enable the human handler to keep hold of the salivette ${ }^{\circledR}$ while the horse chewed, by means of a cotton thread being stitched down the centre of the swab. The swab was placed in the horse's oral cavity at the height of the third premolar in the maxilla. The sampling period was approximately thirty seconds to prevent destruction of the swab through the horses chewing action. Salivettes ${ }^{\circledR}$ were refrigerated at $4^{\circ} \mathrm{C}$ for no longer than two hours before they were transferred and frozen at $-20^{\circ} \mathrm{C}$ until analysis. The saliva was 
analyzed for cortisol using a commercially available Enzyme-linked immunosorbent assay (ELISA) (DRG Diagnostics). A total of three salivary cortisol assays were used for this study. The $\%$ coefficient of variation of means for high control was $3.9 \%$ and the coefficient of variation of means for low control was $15 \%$. The mean inter-assay coefficient of variation was $9.5 \%$.

Saliva was sampled ten minutes and five minutes pre sham clipping, immediately prior to the onset of sham clipping and then every ten minutes thereafter until thirty minutes post onset of sham clipping (a total of six sample times). Cortisol concentration was calculated for each horse / sample time $(\mathrm{ng} / \mathrm{ml})$. The distribution of the data was tested using the Kolmogorov-Smirnov test and subsequently nonparametric analysis was used. Comparison of $\mathrm{C}$ and $\mathrm{NC}$ groups was carried out using the Mann Whitney-U test. The overall effect of sampling time on salivary cortisol concentration was assessed using the Friedman test, with changes in salivary cortisol concentration between each sample time being identified using the Wilcoxon test.

\subsubsection{Eye and core temperature}

Using a thermal camera (Flir ThermaCAM SC640) static thermal images were captured at a distance of 1 meter \pm 50 centimetres from each side of the horse (at an angle of $90^{\circ}$ ). Thermal images of the right and left lateral aspect of the horse were recorded every five minutes from five minutes pre onset of clipping until thirty minutes post onset of sham clipping. These images were collected immediately prior to saliva sampling at the relevant time points to avoid the potential impact of saliva collection on this measure. Clipping began immediately following the last pre clip sample.

Images were uploaded to analytical software (FLIR Quickreport) and extraction of the maximum temperature for the eye was performed. Eye temperature analysis recorded maximum temperature within the palpebral fissure around the entire eyelid margin from the lateral commissure to the lacrimal caruncle. Mean maximum temperature of left and right eye was calculated for each horse for each time point $\left({ }^{\circ} \mathrm{C}\right)$.

Core temperature was recorded at each data sampling time using a digital thermometer (Boots, UK) inserted $2 \mathrm{~cm}$ into the rectum. Ambient temperature at each sample time was recorded using a small, portable temperature data logger (Lascar ELUSB-2). 
Data (eye and core temperatures) did not vary significantly from the normal distribution (Kolmogorov-Smirnov test). A mixed between-within subject analysis of variance (ANOVA) was conducted to assess the impact of group (C / NC) and sample time on temperature, in addition to the interaction between the two variables. Specific differences in temperature at each individual sampling time were investigated using a paired samples t-test.

\subsection{Investigating correlation between measures}

It was predicted that there would be a time lag between the onset of sham clipping and any increase in salivary cortisol concentration and that this would differ from changes in the other measures. To enable the different measures to be compared, changes from baseline to maximum value were calculated for both behavioral and physiological measures (activity score, heart rate, salivary cortisol concentration and eye temperature). None of the resultant data sets varied significantly from the normal distribution (Kolmogorov-Smirnov test) and the relationship between each measure was investigated using the Pearson product-moment correlation coefficient.

Correlation between eye, core and ambient temperature during each trial/ (for each individual horse) was investigated (Spearman Rank correlation).

\section{Results}

\subsection{Behavioral assessment}

When the mean behavior scores attributed to the two groups of animals were compared it was found that at each phase in the study the $\mathrm{NC}$ horses were significantly more active / less relaxed than the $\mathrm{C}$ horses. The Mann-Whitney U test revealed the most significant difference in activity between $\mathrm{C}$ and $\mathrm{NC}$ during the clipping phase $(\mathrm{U}=0.000, \mathrm{z}=-2.643, \mathrm{p}=0.008)$. The least difference in activity occurred before the clipping procedure (baseline: $\mathrm{U}=2.000, \mathrm{z}=-2.193, \mathrm{p}=0.028$ ), with the post sham clipping phase showing more difference in activity between the groups, although less than during the clipping procedure $(\mathrm{U}=1.000, \mathrm{z}=-2.432, \mathrm{p}=$ 0.015). The greatest effect of $\mathrm{C} / \mathrm{NC}$ on activity was found during sham clipping $(\mathrm{r}=$ $0.84)$, followed by post sham clipping $(\mathrm{r}=0.77)$ and baseline / pre-clipping $(\mathrm{r}=0.69)$.

When the activity / behavior of $\mathrm{C}$ and $\mathrm{NC}$ at each phase of the trial was compared it was found that in the $\mathrm{C}$ group there was no significant difference in behavior / activity in the different phases, although the results showed a strong trend (Friedman test: $\mathrm{X}^{2}$ 
$=5.778(2, \mathrm{n}=5), \mathrm{p}=0.056)$. In the $\mathrm{NC}$ group there were significant differences in behavior / activity at each phase (Friedman test: $\mathrm{X}^{2}=7.6(2, \mathrm{n}=5), \mathrm{p}=0.022$ ). Behavior varied significantly between the baseline and clipping phases (Wilcoxon test: $\mathrm{z}=-2.023, \mathrm{p}=0.043)$ and between the clipping and post sham clipping phases $(\mathrm{z}=$ 2.032, $\mathrm{p}=0.042$ ) with the horses being more behaviorally active while being clipped. $\mathrm{NC}$ behavior did not vary between baseline and sham clipping phases $(\mathrm{z}=-0.135, \mathrm{p}=$ 0.892). Given the strong trend towards there being a significant difference in the behavior of the $\mathrm{C}$ horses during the different phases of the trial this was explored further and it was found that although their behavior did not vary significantly between baseline and clipping phases $(\mathrm{z}=-1.219, \mathrm{p}=0.223)$ or between baseline and post sham clipping phases $(\mathrm{z}=-1.0689, \mathrm{p}=0.285)$, the horses were significantly more behaviorally active during the clipping phase than during the post clipping phase $(\mathrm{z}=$ -2.032, $\mathrm{p}=0.042)$. Mean behavioral activity scores for each group of horses ( $\mathrm{C}$ and NC) and for all horses combined are shown in Table 2.

Table 2: Mean behavioral activity scores for each group of horses (C and NC) and overall at each phase of the trial ${ }^{\mathrm{b}}$.

HORSE GROUP

\begin{tabular}{lccc}
\hline & Baseline & Clipping & Post Clipping \\
Compliant (C) & $1.7 \pm 0.38^{*} \mathbf{1}^{*}$ & $1.9 \pm 0.13^{* *}$ & $1.6 \pm 0.23^{*} \mathbf{1}^{*}$ \\
Non-compliant $(\mathrm{NC})$ & $2.7 \pm 0.55^{*} \mathbf{2}^{*}$ & $3.5 \pm 0.87^{* *} \mathbf{2}^{* * 3^{*}}$ & $2.8 \pm 0.93^{*} \mathbf{3}^{*}$ \\
\hline All horses & $2.2 \pm 0.70^{*}$ & $2.7 \pm 1.034^{*} 5^{* *}$ & $2.2 \pm 0.885^{* *}$ \\
\hline
\end{tabular}

${ }^{\mathrm{b}}$ Mean behavioral activity scores \pm standard deviations are shown for each group of horses and overall. Both groups had increased behavioral activity during the clipping phase of the study and behavior before and after the procedure did not vary. The highest activity score was attributed to the NC group during clipping, the lowest to the $C$ group post clipping. At no stage were the C horses as active as the NC horses. Significant difference between groups identified: $* p<0.05 ; * * p<0.01$. Significant difference within groups are identified numerically in subscript, followed by $* p<0.05$ or ** $p<0.01$. 


\subsection{Heart rate}

Although the $\mathrm{HR}$ of the $\mathrm{NC}$ horses was higher than that of the $\mathrm{C}$ horses during all phases of the trial it was only at 10 minutes after the clipping had commenced that this difference was significant (Mann Whitney- $U$ : $U=0.000, z=-2.619, p=0.009$ ). See Figure 1.

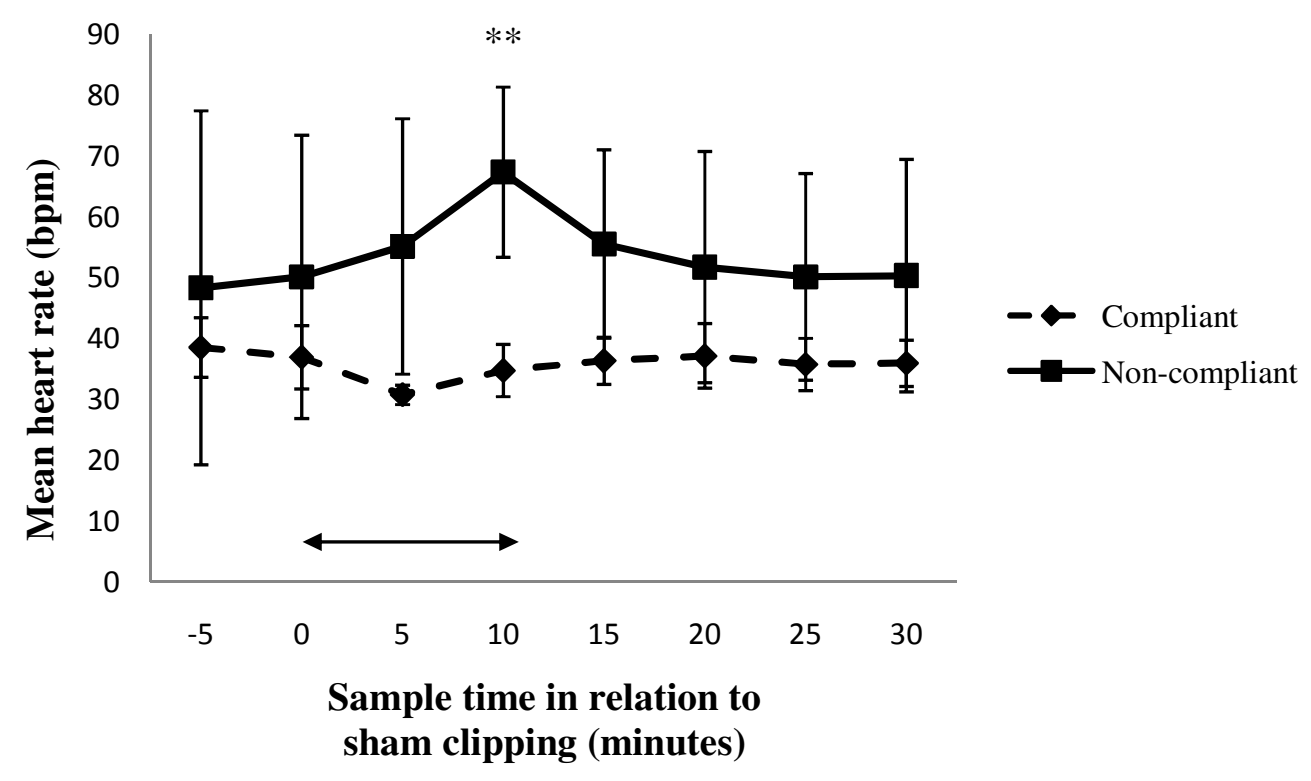

Figure 1: Mean heart rate ( \pm standard deviation) of $C$ and $N C$ horses throughout the sham clipping trial. The first sample point was at 5 minutes before clipping commenced. The 10 minutes when sham clipping took place is indicated by the horizontal arrow (0-10 minutes). Sampling finished after a further 20 minutes. ** Indicates the time point where the NC group had significantly higher HR than the $C$ group $(p<0.01)$. This occurred at the end of the 10 minute clipping period.

No overall effect of time of sampling on HR was found for either group or for ALL horses considered together (Friedman test: all horses $X^{2}=7.116(7, n=10) p=0.417$; $\left.C X^{2}=13.195(7, n=5) p=0.067 ; N^{2}=8.373(7, n=5) p=0.301\right)$. However a significant increase in HR was found between sampling points +5 (mean of $43 \pm$ $19.02 \mathrm{bpm}$ ) and +10 minutes (mean of $51 \pm 19.75 \mathrm{bpm}$ ) (during the sham clipping procedure) for all horses (Wilcoxon test: $\mathrm{z}=-2.301, \mathrm{p}=0.021$ ). When the groups were considered separately there were found to be significant differences in HR at specific time points in the trial in the $\mathrm{C}$ group. HR was significantly lower at +5 minutes of sham clipping compared to immediately prior to the procedure (Wilcoxon test: $\mathrm{z}=-2.023, \mathrm{p}=0.043),+10$ minutes after sham clipping commenced $(\mathrm{z}=-2.06, \mathrm{p}$ $=0.039), 5$ minutes after sham clipping stopped $(\mathrm{z}=-2.032, \mathrm{p}=0.042)$ and at the end 
of the trial period $(\mathrm{z}=-2.023, \mathrm{p}=0.043)$. The only significant difference in the HR of the NC group was found between the end of the 10 minute sham clipping procedure and at 25 minutes after the start, with the former being significantly higher $(\mathrm{z}=-0.023$, $\mathrm{p}=0.043)$. See Figure 1 .

\subsection{Salivary cortisol}

In all of the horses salivary cortisol concentration peaked at 20 minutes after the start of the sham clipping procedure. See Figure 2. Salivary cortisol concentration was significantly higher in ALL horses than at 5 minutes before the start of the sham clipping (Wilcoxon test: $\mathrm{z}=-2.652, \mathrm{p}=0.008$ ) and when the NC group were considered separately salivary cortisol concentration was again significantly higher 20 minutes after the start of the sham clipping procedure than at 5 minutes before the procedure started $(\mathrm{z}=-2.023, \mathrm{p}=0.043)$. It was also significantly lower at this point in NC than immediately before the sham clipping commenced $(z=-2.023, p=0.043)$. Although the highest concentration of salivary cortisol was found in $\mathrm{C}$ group, no significant changes in cortisol concentration were found between any phases of the trial.

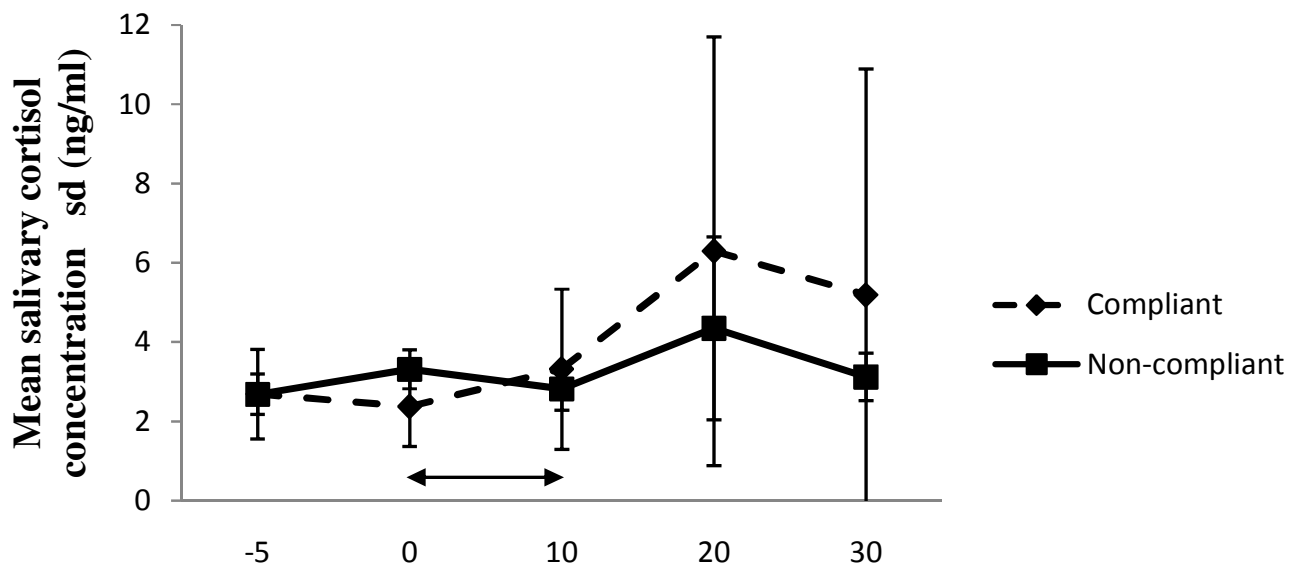

Sample time in relation to sham clipping (minutes)

Figure 2: Mean salivary cortisol concentration ( \pm standard deviation) of $C$ and $N C$ horses throughout the sham clipping trial. The first sample point was at 10 minutes before clipping commenced (see Table 3) but this time has been omitted here to allow comparison with the other measures. No significant differences between $C$ and NC were found at any of the sample times. The 10 minutes when sham clipping took place is indicated by the horizontal arrow (0-10 minutes). 
In ALL horses and when $\mathrm{C}$ and $\mathrm{NC}$ were considered separately, salivary cortisol concentration after the sham clipping was higher than before the procedure. It had decreased post peak at +20 minutes but had not returned to baseline level. The Mann Whitney-U test found no significant difference in salivary cortisol concentration between groups $\mathrm{C}$ and NC during any phase of the study. See Table 3.

Table 3: Salivary cortisol concentrations at each phase of the trail $(C, N C, A L L)^{\mathrm{a}}$

\begin{tabular}{|c|c|c|c|c|c|c|}
\hline $\begin{array}{l}\text { HORSE } \\
\text { GROUP }\end{array}$ & MEA & $\begin{array}{r}\text { SALIVAR } \\
\text { A }\end{array}$ & $\begin{array}{l}\text { CORTISC } \\
\Gamma \text { EACH SA }\end{array}$ & $\begin{array}{l}\text { CONCE } \\
\text { MPLE TII }\end{array}$ & $\begin{array}{l}\text { TRATION } \\
\text { E }\end{array}$ & $\mathrm{g} / \mathrm{ml})$ \\
\hline $\begin{array}{l}\text { SAMPL } \\
\text { E TIME }\end{array}$ & -10 & -5 & $\mathbf{0}$ & 10 & 20 & 30 \\
\hline $\mathrm{C}$ & $2.9 \pm 1.17$ & $2.68 \pm 1.13$ & $2.37 \pm 1.00$ & $\begin{array}{c}3.31 \pm 2.0 \\
2\end{array}$ & $6.29 \pm 5.41$ & $\begin{array}{c}5.18 \pm 5.7 \\
1\end{array}$ \\
\hline $\mathrm{NC}$ & $\begin{array}{c}2.97 \pm 0.5 \\
6\end{array}$ & $2.68 \pm 0.51 *$ & $\begin{array}{c}3.31 \pm 0.49 \\
*\end{array}$ & $\begin{array}{c}2.82 \pm 0.5 \\
4\end{array}$ & $4.34 \pm 2.31 *$ & $\begin{array}{c}3.12 \pm 0.6 \\
0\end{array}$ \\
\hline ALL & $\begin{array}{c}2.92 \pm 0.8 \\
6\end{array}$ & $\begin{array}{c}2.68 \pm 0.83^{*} \\
*\end{array}$ & $2.84 \pm 0.89$ & $\begin{array}{c}3.06 \pm 1.4 \\
2\end{array}$ & $\begin{array}{c}5.32 \pm 4.05 * \\
*\end{array}$ & $\begin{array}{c}4.15 \pm 3.9 \\
8\end{array}$ \\
\hline
\end{tabular}

${ }^{a}$ This table shows the mean values for salivary cortisol concentration $(\mathrm{ng} / \mathrm{ml}) \pm$ standard deviation, for each of the sample times (designated in terms of minutes before or after the commencement of the sham clipping procedure). Sham clipping commenced immediately after saliva collection at sample time $0 . *$ and $* *$ denote significant differences in salivary cortisol concentration at these sample times for each group of horses $(C, N C, A L L)$ with * indicating significance at $p<0.05$ and ** indicating significance at $p<0.01$. The highest salivary cortisol concentration in all groups was found at 20 minutes after the start of the sham clipping. In all groups the lowest salivary cortisol concentration was found at times prior to the sham clipping.

\subsection{Eye and core temperature}

Eye temperature: The results of the mixed between-within analysis of variance (ANOVA) showed that there was a significant main effect of sample time on mean eye temperature, which increased until the end of the sham clipping procedure, after which it then decreased (Wilks Lambda $=0.009, \mathrm{~F}(7,2)=32.68, \mathrm{p}=0.03$, partial eta 
squared $=0.991)$. See Figure 2. Although there was no effect of group $(\mathrm{C} / \mathrm{NC})$ on eye temperature $(\mathrm{F}(1,8)=0.36, \mathrm{p}=0.57)$ there was a significant interaction between group and sample time (Wilks Lambda $=0.008, \mathrm{~F}(7,2)=34.27, \mathrm{p}=0.029$, partial eta squared $=0.992$ ). Although both groups showed comparable rises in eye temperature until the end of the sham clipping procedure, the NC group showed a greater decrease in eye temperature immediately afterwards. By the final sampling time the two groups again had similar eye temperatures. See Figure 3. In both groups the highest eye temperature was recorded 10 minutes after the start of the sham clipping.

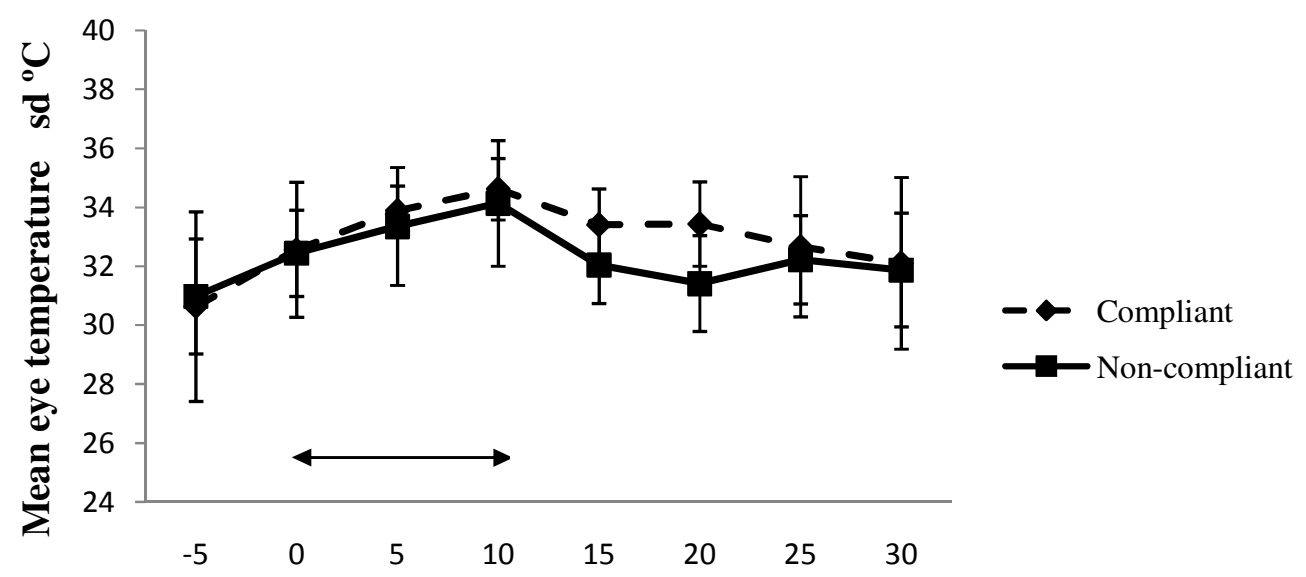

Sample time in relation to sham clipping (minutes)

Figure 3: Mean eye temperature ( \pm standard deviation) of $C$ and $N C$ horses throughout the sham clipping trial. The first sample point was at 5 minutes before clipping commenced. The 10 minutes when sham clipping took place is indicated by the horizontal arrow (0-10 minutes). Sampling finished after a further 20 minutes.

At the start of the trial ( -5 minutes) eye temperature was significantly lower than at any other time in the trial (paired samples t-test: $p<0.05$ ). A significant increase in eye temperature was found between 0 and +5 minutes into the sham clipping procedure and again between +5 and +10 minutes into the procedure $(\mathrm{p}<0.05)$. There was then a substantial decrease in eye temperature between +10 minutes (when the sham clipping ceased) and +15 minutes $(\mathrm{p}=0.003)$. No significant differences in eye temperature were found between the other sample times $(0,+15,+20,+25,+30$ minutes).

Core temperature: The results of the mixed between-within analysis of variance (ANOVA) showed that although there was no interaction between sample time and 
group, or of sample time per se, group $\mathrm{C}$ had significantly higher core temperatures than group $\mathrm{NC}\left(\mathrm{C}: 37.45 \pm 0.19^{\circ} \mathrm{C}\right.$; $\left.\mathrm{NC}: 36.99 \pm 0.36{ }^{\circ} \mathrm{C}\right)(\mathrm{F}(1,8)=7.389, \mathrm{p}=0.026$, partial eta squared $=0.48$ ).

Mean ambient temperature ranged from $3.78 \pm 1.37{ }^{\circ} \mathrm{C}$ to $11.26 \pm 0.34{ }^{\circ} \mathrm{C}$ for the different trials. No correlation was found between ambient temperature, eye temperature and core temperature for any of the horses.

\subsection{Correlation between measures}

There was a positive correlation between increase in salivary cortisol concentration and increase in eye temperature, $\mathrm{r}=0.681, \mathrm{n}=10, \mathrm{p}=0.03$. No significant correlations were found between any of the other measures.

\section{Discussion}

The results of the sham clipping trial suggest that even though this procedure was unlikely to be painful, it was an aversive experience for the animals tested. In this trial hair was not actually clipped from the coat and the duration of the procedure was considerably shorter than it would have been during everyday management (when it would take approximately 45 minutes in total). Although five of the horses were assessed as being compliant with the procedure, ALL of the animals tested showed behavioral and physiological changes that were associated with the sham clipping phase. When all horses were considered together it was found that during sham clipping behavioral activity increased. Heart rate increased significantly after the first five minutes of sham clipping, peaking just before the procedure ceased. Salivary cortisol concentration peaked at twenty minutes after sham clipping had started and eye temperature increased significantly five minutes into the procedure $\left(+1.12^{\circ} \mathrm{C}\right)$ and again between five and ten minutes into the procedure $\left(+0.75^{\circ} \mathrm{C}\right)$. An increase in eye temperature occurred prior to the sham clipping but this was not significant. However, when compared to this baseline temperature, eye temperature showed an increase of $3.56^{\circ} \mathrm{C}$ when it peaked at the end of the sham clipping.

When the two groups were compared, those that were classed as being non-compliant with the clipping procedure were found to exhibit less relaxed, more active behavior than the compliant group at all phases of the study. This difference was greatest during sham clipping and so was consistent with their categorization as non-compliant. 
The higher heart rate of the non-compliant group at all phases of the study could relate to this increased activity, with the comparative increase in activity during sham clipping resulting in an increase in the difference in heart rate at the end of the procedure. At the start of the sham clipping the heart rate of the compliant group dropped (see Figure 1) and this may be due to a lack of activity at the start of the procedure. Animals trained to accept such procedures will tend to stand stiller and appear compliant. However, the behavioral scores still suggest an increase in activity from baseline so there may be an alternative explanation for this. Despite such behavioral differences between the two groups and differences in heart rate, there was no overall group-related difference in salivary cortisol concentration or eye temperature. However, higher core temperatures were found in the compliant group which may suggest that they found the procedure aversive but this was not apparent in their behavioral response. Further investigation into the effect of aversive procedures on core temperature is required. Differences between horses in behavioral response were not reflected in differences in cortisol / eye temperature response. Such physiological measures enable a more objective assessment of the impact of a procedure on an animal, regardless of the level of behavioral training and compliance.

The peak in salivary cortisol concentration twenty minutes post onset of sham clipping indicated that the procedure did cause a stress-related physiological response that was not wholly consistent with behavioral findings. Significant increases in salivary cortisol concentration occurred in ALL horses. Although the rise in salivary cortisol concentration was not statistically significant in the compliant horses, this group had both the highest mean concentration at twenty minutes post onset of the sham clipping and the greatest variation in this measure (as demonstrated by the standard deviations). As in previous studies $[11,15]$ there was a time delay in the elevation of the cortisol concentration post stressor and this had not dropped to baseline level by the last sampling time, thirty minutes post onset of sham clipping. In ALL horses and when the compliant group were considered alone, salivary cortisol concentration had increased by ten minutes post stressor, as found by Shanahan in a study into the stress associated with loading horses into a transportation trailer [32]. The NC group of horses showed earlier signs of increased cortisol concentration at ten minutes after they had been tied up in preparation for the trial. It is possible that this 
resulted from the onset of restraint and the anticipation of an imminent procedure. See Table 3.

Increases in salivary cortisol concentration indicated that the sham clipping procedure was indeed an aversive procedure. Although there was no correlation between behavioral scores, heart rate changes and cortisol, there was a significant correlation between increases in eye temperature and hormonal response. Eye temperature in all horses peaked at ten minutes after the onset of the sham clipping. However, this was immediately before the procedure ceased and it cannot be assumed that this rise would not continue if the procedure was of longer duration or whether the peak temperature had been reached. In normal management the clipping procedure would take longer, generally approximately 45 minutes or longer. When compared with temperature changes associated with emotional responses in other species $\left(0.1^{\circ}-0.2^{\circ}\right.$ $\mathrm{C}$ in rhesus monkeys during presentation of a potentially threatening handler [17]; $0.9^{\circ} \mathrm{C}$ in dairy cows following catheterization procedure [15]) the total increase in temperature found in this study was quite large $\left(+3.56^{\circ} \mathrm{C}\right.$ from baseline). Increases after shorter durations of sham clipping were found to be closer to the changes found in other studies $[15,17]$, being $+0.75^{\circ} \mathrm{C}$ and $+1.12^{\circ} \mathrm{C}$ after five and ten minutes into the procedure respectively. Temperature changes in the case of the rhesus monkeys [17] occurred within 10-110 seconds of the appearance of the stressor and in order to determine the true speed of this response in the horse, additional sampling times post stressor are required. Decreases in eye temperature occurred immediately after the procedure had ceased but did not reach baseline levels at the end of the sampling period, possibly because of the metabolic consequences of the hormonal stress response.

Activation of the sympathetic nervous system in response to potentially threatening / aversive stimuli would account for the immediate increase in heart rate post onset of stressor. However, this measure can be confounded by the influence of activity level on heart rate. Instantaneous increases in temperature around the eyes have been reported in humans in response to auditory startle tests and linked to the fright / flight response mediated by the sympathetic nervous system [33]. The correlation between increases in salivary cortisol and eye temperature in the horse suggest that, at least in this species, the latter measure can provide an objective, non-invasive assessment of the aversive nature of management procedures. The instantaneous nature of the 
response would allow precise evaluation of the effect of specific procedures without the need for costly and delayed hormonal analyses.

Considerable individual variation was found in both hormonal and eye temperature values so it is imperative that baseline values are used to assess changes in response to stimuli. In addition, there was variation in these physiological responses that did not correlate with observed variation in behavior. Consequently behavior was not an accurate indicator of whether the animal found the procedure aversive or not. Although previous training and individual behavioral differences appear to have resulted in some animals accepting and being behaviorally compliant during management procedures, the relatively high levels of salivary cortisol and increases in eye temperature recorded in the compliant group suggest that they do indeed experience stress during such procedures. Masking signs of fear when escape is not possible may be a survival strategy [1]. The restriction of natural behavioral responses in stressful situations may also be compensated for by increases in the physiological response, with reduced behavioral response being stressful per se. The inhibition of natural behavior and associated stress has been found to contribute to the development of abnormal behavior patterns [34] and ill health [35] in animals. It is therefore important that the aversive nature of animal management procedures is evaluated and this cannot be done on the basis of behavioral evidence alone.

\section{Conclusion}

The results of this study support the potential use of IRT to monitor the response of animals to a variety of procedures and to provide us with objective evidence regarding the nature of their response. This measure could be used by animal managers to accurately interpret the behavioral responses of animals. As noted by McAfferty [19] we would concur that given the recent advances in IRT technology and a reduction in the cost of the equipment and software, monitoring surface temperature changes (in particular those of the eye and surrounding area) will provide readily available information that can be used to improve animal management and welfare.

\section{Acknowledgements}

We would like to thank staff and students at the Brackenhurst Equestrian Centre, Nottingham Trent University for their support during this study. In particular, thank you to Rachel Kay for collecting the video footage. Also, thank you to Cheryl Wells 
(School of Science and Technology, Nottingham Trent University) for laboratory support throughout.

\section{References}

[1] Berger A, Scheibe KM, Michaelis S, Streich, WJ. Evaluation of living conditions of free-ranging animals by automated chronobiological analysis of behavior. Behavioral Research Methods, Instruments and Computers 2003; 35: 458-466.

[2] Seaman SC, Davidson HPB, Waran NK. How reliable is temperament assessment in the domestic horse (Equus caballus)? Applied Animal Behavior Science 2002; 78: 175-191.

[3] Hall C, Goodwin D, Heleski C, Randle H, Waran N. Is there evidence of learned helplessness in horses? Journal of Applied Animal Welfare Science 2008; 11: 249266.

[4] Mormède P, Andanson S, Aupérin B, Beerda B, Guémené D, Malmkvist J, Manteca X, Manteuffel G, Prunet P, van Reenen CG, Richard S, Veissier I. Exploration of the hypothalamic-pituitary-adrenal function as a tool to evaluate animal welfare. Physiology and Behavior 2007; 92: 317-339.

[5] Hopster H, van der Werf JT, Erkens JH, Blokhuis HJ. Effects of repeated jugular puncture on plasma cortisol concentrations in loose-housed dairy cows. Journal of Animal Science 1999; 77: 708-714.

[6] Irvine CHG, Alexander SL. The effect of social stress on adrenal axis activity in horses: the importance of monitoring corticosteroid binding globulin capacity. Journal of Endocrinology 1998; 157: 425-432.

[7] Bayazit V. Evaluation of cortisol and stress in captive animals. Australian Journal of Basic and Applied Sciences 2009; 3: 1022-1031.

[8] Vinning RF, McGinley RA, Symons RG. Hormones in saliva: Mode of entry and consequent implications for clinical interpretation. Clinical Chemistry 1983; 29: 1752-1756.

[9] Van der Kolk JH, Nachreiner RF, Schott HC, Refsal KR, Zanela AJ. Salivary and plasma concentration of cortisol in normal horses and horses with cushings disease. Equine Veterinary Journal 2001; 33: 211-213.

[10] Le Roux CW, Sivakumaran S, Alaghband-Zadeh J, Dhillo W, Kong WM, Wheeler MJ. Free cortisol index as a surrogate marker for serum free cortisol. Annals of Clinical Biochemistry 2002; 39: 406-408.

[11] Hughes TJ, Creighton E. Measuring cortisol as an indicator of stress response in domestic horses. Journal of Equine Studies 2007; 4: 26-28.

[12] Lane J. Can non-invasive glucocorticoid measures be used as reliable indicators of stress in animals? Animal Welfare 2006; 15: 331-342.

[13] Jacks DE, Sowash J, Annig J, McGloughlin T, Andres F. Effect of exercise at three exercise intensities on salivary cortisol. The Journal of Strength and Conditioning Research 2002; 16: 286-289.

[14] Eddy AL, Van Hoogmoed LM, Snyder JR. The role of thermography in the management of equine lameness. The Veterinary Journal 2001; 162: 172-181. 
[15] Stewart M, Webster J, Verkerk G, Colyn J, Schaefer A. Non-invasive measurement of stress in dairy cows using infrared thermography. Physiology and Behavior 2007; 92: 520-525.

[16] Eckman P, Levenson RW, Friesen WV. Autonomic nervous system activity distinguishes between emotions. Science 1983; 221: 1208-1210.

[17] Nakayama K, Got S, Karaoke K., Nakamura, K. Decrease in nasal temperature of rhesus monkeys (Macaca mulatto) in negative emotional state. Physiology and Behavior 2005; 84: 783-790.

[18] Lowe TE, Cook CJ, Ingram JR, Harris PJ. Changes in ear-pinna temperature as a useful measure of stress in sheep (Ovis aries). Animal Welfare 2005; 14:35-42.

[19] McCafferty DJ. The value of infrared thermography for research on mammals: previous applications and future directions. Mammal Review 2007; 37: 207-223.

[20] Cook NJ, Schaefer AL, Church JS. Nutritional therapy modulates stress responses of elk (Cervus elaphus Canadensis) to removal of velvet antler. Online Journal of Veterinary Research 2006; 10: 20-25.

[21] Cook NJ, Schaefer AL, Warren L. Adrenocortical and metabolic responses to ACTH injection in horses: An assessment by salivary cortisol and infrared thermography of the eye. Canadian Journal of Animal Science (abstract of technical paper) 2001; 81: 621 .

[22] Sapolsky RM. Why zebras don't get ulcers. New York: WH Freeman and Company; 1999.

[23] Mason GJ. Stereotypy: a critical review. Animal Behavior 1991; 41: 1015-1038.

[24] Rietmann TR, Stuart AEA, Bernasconi P, Stauffacher M, Auer JA, Weishaupt MA. Assessment of mental stress in warmblood horses: heart rate variability in comparison to heart rate and selected behavioral parameters. Applied Animal Behavior Science 2004; 88: 121-136.

[25] Rivera E, Benjamin S, Nielson B, Zanella AJ. Behavioral and physiological responses of horses to initial training: the comparison between pastured versus stalled horses. Applied Animal Behavior Science 2002; 78: 235-252.

[26] Forkman B, Boissy A, Meunier-Salaün MC, Canali E, Jones RB. A critical review of fear tests used on cattle, sheep, poultry and horses. Physiology and Behavior 2007; 92: 340-374.

[27] Mackenzie SA, Giordano AP, Monahan EA. Use of a conditioned stimulus to improve equine behavior in response to clipping. Equine Practice 1987; 9: 15-17.

[28] Gough MR. Nursing notes: Clipping horses. Equine Veterinary Education 1997; 9: $161-165$.

[29] Gough MR. A note on the use of behavioral modification to aid clipping ponies. Applied Animal Behavior Science 1999; 63: 171-175.

[30] Lebelt D, Schönreiter S, Zanella AJ. Salivary cortisol in stallions: the relationship with plasma levels, daytime profile and changes in response to semen collection. Pferdeheilkunde 1996; 12: 411-414. 
[31] Van der Kolk JH, Nachreiner RF, Schott HC, Refsal KR, Zanella AJ. Salivary and plasma concentration of cortisol in normal horses and horses with Cushing's disease. Equine Veterinary Journal 2001; 33: 211-213.

[32] Shanahan S. Trailer loading stress in horses: Behavioral and physiological effects of non-aversive training (TTEAM). Journal of Applied Animal Welfare Science 2003; 6: 263-274.

[33] Levine JA, Pavladis I, Cooper M. The face of fear. The Lancet 2001; 357:1757.

[34] McGreevy PD, Cripps PJ, French NP, Green LE, Nicol, CJ. Management factors associated with stereotypic and redirected behavior in the thoroughbred horse. Equine Veterinary Journal 1995; 27: 86-91.

[35] Barnett JL, Hemsworth PH. The validity of physiological and behavioral measures of animal welfare. Applied animal Behavior Science; 25: 177-187. 